\title{
A LEGISLAÇÃO APARENTE NA CONSTRUÇÃO DE UMA CONSTITUCIONALIZAÇÃO SIMBÓLICA E SEUS EFEITOS NA PROTEÇÃO AO MEIO AMBIENTE
}

Arnaldo Silva JúnIOR

Mestre e Doutorando em Direito Público pela PUC-Minas.

Edimur Ferreira de Faria

Mestre e doutor em Direito Administrativo pela UFMG, professor da Graduação e do Programa de Pós-graduação em Direito da PUC Minas, Ex-Diretor da Faculdade Mineira de Direito da PUC Minas e Ex-Presidente do Instituto Mineiro de Direito Administrativo.

\section{Resumo}

O desenvolvimento do Estado Democrático de Direito exige, além da valorização, a efetividade dos direitos fundamentais presentes na Carta Constitucional. Nesse contexto debate-se e analisa-se o atual sistema normativo brasileiro, a partir de um enfoque biopolítico e da microfísica do poder, procurando desvendar possível influência ideológica nos processos legislativos. Analisou-se, ainda, partindo do conceito de legislação simbólica, conteúdos legislativos que conduzem a uma ineficácia ou desvirtuamento de resultados normativamente propostos, visando atender exclusivamente a propósitos ideológicos bem definidos. Busca-se nesse contexto, analisando os discursos de elaboraçáo legislativa e os resultados normativos alcançados, definir conceito de legislação aparente, objetivando verificar a utilização do Direito como instrumento de sustentação de interesses de uma classe dominante, por meio de um processo de universalizaçáo abstrata de ideias, que camuflam a existência concreta de objetivos particulares de determinada classe social. A utilização dessa legislação aparente, por meio de processo biopolítico, poderá ser compreendida como forma de aquietação social para condução a um fim conveniente de manutenção de interesses. A produção de legislação aparente que integra e constitui ordenamento jurídico infraconstitucional, acaba por influenciar a aplicabilidade das normas constitucionais, muitas vezes funcionando como agente de transformação interpretativa da Constituição a serviço de interesses socialmente limitados. Por fim, verifica-se que essa legislaçâo aparente produz efeitos diretos e dificulta açôes de proteção ao meio ambiente. 


\section{Palavras-chave}

Legislação simbólica; Processos legislativos; Biopolítica; Processos ideológicos; Estado; Poder; Proteção; Meio ambiente.

\section{Abstract}

The development of a democratic state requires beyond recovery, the effectiveness of fundamental rights in the present Constitutional Charter. In this context, it is proposed to discuss and analyze the normative positivist system, from a biopolitical approach and the microphysics of power, seeking to uncover a possible ideological influence on legislative processes. The aim is also based on the concept of symbolic legislation, examine some of the content of legislation that lead to inefficiency or distortion of results normatively proposed, aiming only to serve ideological purposes well defined. Search in that context, analyzing the speeches of lawmaking and the results achieved normative, defining a concept of law apparent, to verify the use of law as an instrument to support the interests of a ruling class, through a process of universalization and apparent abstract ideas, which camouflage the concrete existence of particular goals of a particular class. The apparent use of such legislation through a biopolitical process may be understood as a way of calming a social order to conduct the maintenance of appropriate interests. The production of an apparent law that integrates and constitutes a legal infra, ultimately influence the applicability of constitutional norms, often functioning as a processing agent interpreting the Constitution. Finally, check that this apparent law produces direct effects and hinders protection actions to the environment.

\section{Key words}

Symbolic law; Legislative proceedings; Biopolitics; Ideological process; State; Power; Protection; Environment.

\section{Introdução}

O processo legislativo no Brasil, na sua compreensão como ato de elaboração e produção de leis, tem sido tratado à luz de uma visão positivista, na qual persiste evidente "concepção instrumental do Direito Positivo, no sentido de que as leis constituem meios insuperáveis para se alcançar determinados fins desejados pelo legislador, especialmente a mudança social” (NEVES, 2011, p. 29), traduzindo verdadeira e inequívoca influência daqueles que compreendem o Direito como objeto de um conhecimento jurídico, que constitui ordem normativa da conduta humana, ou seja, um sistema de normas que regulam o comportamento humano (KELSEN, 2006, p. 5). 
Essa compreensão positivista, da qual compartilha-se da crítica quanto a sua implicaçáo conceitual de um modelo funcional simplista e ilusório (NEVES, 2011, p. 29), parte do pressuposto de que por meio da codificação possa se alcançar resultados seguros como instrumento de controle social. Esse pensamento ignora a complexidade das relaçôes sociais e políticas, reduzindo o sistema jurídico a uma visão exclusivamente instrumental, alicerçando-se ainda, numa "ideia iluminista de que uma boa lei possa resolver nossos problemas" (CRUZ, 2007, p. 270).

Além disso, a ideia de legislação como solução imediata para regulação e controle social, constantemente esconde outros propósitos da norma, carregados por processos ideológico ${ }^{1}$, que simulam uma atmosfera universalista de situaçôes tratadas, quando na verdade, direcionam-se para foco bem definido de interesses particulares e reducionistas de uma classe específica.

As normas, nesse processo de elaboração, acabam por se transformar em símbolos de um objetivo superficialmente concebido e apresentado, que servirão como sustentáculo de um sistema biopolítico do Estado, para manutenção de interesses quase sempre econômicos, num mecanismo circular de alimentação da rede microfísica de poder ${ }^{2}$. Em suma, aquilo que parece ser, muitas vezes em nada é, quando se trata de legislação compreendida de modo finalístico pelo legislador.

Sem considerar análise mais crítica de hermenêutica constitucional, com foco nas influências existentes na dinâmica de elaboração legislativa, no conteúdo e nos resultados extraídos do próprio texto da realidade social; o objetivo primeiro é o de verificar se há, por meio da aplicação das normas simbólicas, a caracterização de uma legislação aparente, que age como mecanismo de transformação interpretativa das normas constitucionais, induzindo a um evento de constitucionalização simbólica.

\section{A Legislação Simbólica e os Discursos de Verdade}

Dispensa-se o aprofundamento da temática específica da conceituação sobre a legislação simbólica, e em virtude do recorte epistemológico. Interessa-se neste trabalho

1 Utilizamos aqui os significados modernos do termo ideologia "não mais empregado para indicar uma espécie de análise filosófica, mas uma doutrina mais ou menos destituída de validade objetiva, porém mantidas por interesses claros ou ocultos daqueles que a utilizam” (ABBAGNANO, 2007, p. 615).

2 "Em uma perspectiva micro, o poder é entendido, não como uma entidade ou algo que tenha um local determinado para acontecer, mas sim como estando em todos os lugares. Não existe 'o poder', mas somente relação de poder. Flutuante, não há alguém que o detenha. É nas práticas cotidianas que ele se realiza. A repetição das relaçóes que estabelecem quem cria as regras e quem as cumpre o mantém presente na mente dos indivíduos. Ele está em todos os lugares onde haja mais de um sujeito, ou seja, todas as relações, de uma forma ou de outra, são relaçôes de poder, mesmo que não percebidas enquanto tais. Sendo uma relação, onde o poder for exercido, existe também uma resistência. Com sucesso ou não, desrespeitar regras ditadas pelos detentores momentâneos de poder é uma forma desta resistência" (LOBO, [s.d.]). 
visualizar o tema nos moldes propostos por Neves (2011, p. 30), uma definição de legislação simbólica atrelada à produção de textos, "cuja referência manifesta à realidade é normativo-jurídica, mas que serve, primária e hipertroficamente, a finalidades políticas de caráter não especificamente normativo-jurídico”.

É a partir desse processo conjuntural de elaboração legislativa, conjugando-se o ato de produção do texto legal com o próprio texto produzido, que se poderá visualizar que em muitas circunstâncias a "referência político-valorativa ou político-ideológica" (NEVES, 2011, p. 31) passa a ser mais relevante que o caráter normativo-jurídico da legislação, tornando-a afastada da exigência social que a originou.

Em síntese, sempre se está diante de legislação simbólica, quando há evidente desvirtuamento de propósitos originários, ou, ainda, quando esses visam apresentar o Estado com roupagem conveniente a determinada classe ou grupo social, reduzindo os resultados pretendidos a segundo plano.

Sem perder de vista a exposição doutrinária sobre o conteúdo que a legislação simbólica pode apresentar ${ }^{3}$, encontra-se enorme relevância em anotar que além de servir a interesses ideologicamente determinados, essa legislação carrega em si, uma lamentável missão de produzir e constituir-se em discurso de verdade para servir aos propósitos dominantes. Em várias oportunidades, Foucault mencionava a criação dos discursos de verdade como mecanismos de poder ${ }^{4}$, o que se pode traduzir nos objetivos de manutenção ou criaçáo de estados de coisas ou mesmo da relação dos próprios sujeitos da realidade social. A compreensão de Foucault é neste sentido:

Temos que produzir a verdade como, afinal de contas, temos de produzir riquezas. E, de outro lado, somos igualmente submetidos à verdade, no sentido de que a verdade é a norma; é o discurso verdadeiro que, ao menos em parte, decide; ele veicula, ele próprio propulsa efeitos de poder (FOUCAULT, 2005, p. 29).

A produção de discursos de verdade é contínua, e o papel que a norma desenvolve nesse contexto é significativo nos dias de hoje, sendo ainda comum e atual a afirmação foucaultiana de que "afinal de contas, somos julgados, condenados, classificados, obrigados a tarefas, destinados a uma certa maneira de viver ou a uma certa maneira de morrer, em função de discursos verdadeiros, que trazem consigo efeitos específicos de poder" (FOUCAULT, 2005, p. 29).

3 Para Neves (2011, p. 33), a legislaçáo simbólica pode se apresentar sobre a forma de três conteúdos: a) confirmar valores sociais; b) demonstrar a capacidade de açâo do Estado e c) adiar a solução de conflitos sociais através de compromissos dilatórios.

4 Foucault (2005, p. 28) dizia que "estudar o como do poder, isto é, tentar apreender seus mecanismos entre dois pontos de referência ou dois limites: de um lado, as regras de direito que delimitam formalmente o poder; de outro lado, a outra extremidade, o outro limite, seriam os efeitos de verdade que esse poder produz $[\ldots] "$. 
A crença na norma, a ideia de que o que a lei diz é uma verdade em si mesma, é um pensamento de senso comum que permeia cotidianamente a sociedade. Esse potencial que se traduz em discurso de verdade contido na norma, é a essência da força indutora que se utiliza a legislação simbólica.

A sobreposição do caráter político ao propósito normativo-jurídico, se dá via discurso de verdade que a norma realiza, num processo de apresentaçáo simbólica que esconde, escamoteia, camufla o seu conteúdo particularizado, ideológico, de interesses limitados e definidos, simulando a melhor proposta de solução para determinado conflito social.

\section{A Influência Ideológica no Desenvolvimento dos Processos Legislativos}

Os discursos de verdade apresentados por meio das normas são reflexos de processos ideológicos que originaram a norma.

Não é recente a identificação de interesses ocultos presentes na elaboração legislativa. Durante vários momentos históricos é possível constatar que determinada norma surgiu apresentando-se como solução para um conflito social específico, mas sua aplicação acabava resultando em fracasso ou desvirtuava seu objetivo original, sendo, em todos os casos, propositadamente concebida com essa finalidade.

A Lei Áurea pode servir como exemplo de uma norma que se apresentava como símbolo de liberdade dos escravos e fim da escravidão, quando, na verdade, era possível verificarem-se outros objetivos, como afirmam estudiosos e historiadores sobre o tema:

Por trás da capa de inclusão e solidariedade para com a população negra escravizada estava o objetivo de beneficiar os senhores das riquezas, das terras e do direito de vida e de morte sobre os afro-brasileiros. Mais do que isso, a grande intenção da sociedade branca era excluir, marginalizar, afastar o negro do direito à terra, à educação, aos cuidados na infância e na velhice (OFM, 2003).

É de conhecimento que surge das pesquisas aos livros de história, quando da edição da Lei Áurea, que apenas $5 \%$ da população negra no Brasil ainda viviam sob o regime de escravidão (OFM, 2003), tendo em vista vários atos oficiais ${ }^{5}$ que permitiram aos negros a

5 A Lei do Ventre Livre e a Lei dos Sexagenários, ambas anteriores à Lei Áurea, são exemplos de normas que possibilitavam a liberdade aos negros. A primeira permitia a liberdade aos recém-nascidos, a partir da publicação daquela Lei, e a segunda concedia a liberdade ao escravo que atingisse 60 anos. Interessante registrar que ambas as leis são consideradas por grupos de estudos da raça negra e associaçóes de afrodescendentes como normas nocivas aos negros, apesar de sua aparência de boa lei. Uma, por separar os filhos recém-nascidos dos pais, com o intuito de evitar a deficiência no trabalho do campo; a outra, argumentam os críticos, por considerar que a liberdade ao negro de 60 anos era uma forma de livrar-se de um problema, uma vez que não mais servia como um boa mão de obra. 
obtenção da liberdade, quase sempre por meio de seus próprios esforços. Essa constatação histórica já permitiria concluir que seria demasiadamente propagandístico a representatividade que a referida lei acabou por encampar, tornando-a, nesse sentido, uma lei simbólica, uma vez que os resultados "propagados" não seriam aqueles efetivamente alcançados com o propósito que "aparentemente" a norma se apresentava.

Outros tantos exemplos poderiam ser elencados, contudo a brevidade que se impóe conduz a uma exposição de maior importância nesta oportunidade. A influência da imprensa no processo de elaboração legislativa, principalmente no âmbito criminal, é escancaradamente perceptível em nosso País, sendo um instrumento motivador para ação ideológica nos processos legislativos.

Em passado razoavelmente recente, a imprensa divulgava, em horários nobres da televisão brasileira, dois atos criminosos praticados contra respeitados empresários brasileiros. Ambos ocorridos em 1989, desencadearam a aprovação mais célere de uma lei na história do Congresso Nacional brasileiro: a Lei n. 8.072, de 25/7/1990, que classificava o crime de sequestro como hediondo (BRASIL, 1990).

Mascarenhas (2010), discorrendo sobre a influência da mídia na produção legislativa penal brasileira, faz menção expressa aos casos de sequestro mencionados, destacando a celeridade procedimental adotada pelo Congresso Nacional, afirmando:

O processo legislativo sumaríssimo de promulgação da referida lei foi pautado, como já dito, pelos sequestros dos empresários Abílio Diniz e Roberto Medina. O Senado aprovou a Lei em apenas 34 dias, contados da data de apresentaçáo do projeto, e a Câmara aprovou um substitutivo a respeito em apenas dois dias.

Esse caso específico de influência da mídia no processo legislativo brasileiro gerou repercussão além dos limites territoriais brasileiros ${ }^{6}$.

Mais adiante, após o assassinato de uma reconhecida atriz em 1994, o Congresso brasileiro, novamente guiado pelos impulsos midiáticos, aprovou a Lei no 8.930 , de 06/9/1994, ampliando o rol de crimes hediondos, ali inserindo o homicídio qualificado.

Essa força influenciadora da mídia junto ao legislador, por consequência, gera a produção de legislação simbólica, de conteúdo ideologicamente contaminado, por objetivos meramente políticos imediatista (dar satisfação à sociedade e à mídia), sem qualquer

6 Os ilustres penalistas Zaffaroni e Pierangeli (2002), fazendo menção a norma originária dos fatos criminosos ocorridos no Brasil e amplamente divulgados, aduziram que "menos de 2 anos após a Constituição Federal de 1988, o legislador ordinário, pressionado por uma arquitetada atuação dos meios de comunicação social, formulava a lei 8.072/90. Um sentimento de pânico e de insegurança - muito mais produto de comunicação do que realidade - tinha tomado conta do meio social e acarretava como consequência imediatas a dramatização da violência e sua politizaçâo. 
compromisso com a efetiva solução dos conflitos sociais que se apresentaram (uma norma que comprovadamente não alcança resultados no combate à criminalidade).

\section{A Concepção de Legislação Aparente}

Um amplo estudo sobre a existência, conceituação, forma, constituição e alcance da legislação simbólica já fora desenvolvido, e de certa forma, poderia dar a impressão de esgotamento do tema, principalmente diante do grau de aprofundamento da pesquisa levada a efeito, e das obras jurídicas produzidas. Contudo, a proposta de debate que se apresenta, tem em seu núcleo, um enfoque que ligeiramente diferencia-se da discussão até agora desenvolvida no campo da doutrina.

O campo de estudo da legislação simbólica tem demonstrado a existência e conceituação dessas normas em um modelo no qual ressalta-se como característica elementar a ausência de resultados, além, é claro, dos elementos básicos de desvirtuamento de propósitos, confirmação de valores, satisfação às expectativas da sociedade ou como compromisso dilatório (NEVES, 2011).

A legislação aparente, que poderia até ser classificada também como legislação simbólica ou como uma de suas formas de apresentação, tem em seu conteúdo detalhe de diferenciação, sutil, ligeiro, e até perigoso, uma vez que num rápido olhar superficial, poder-se-ia, afastá-la dessa categoria. Há no contexto da legislação aparente, a constatação de resultados obtidos pela norma jurídica, e esse fato, assenta e fortalece ainda mais o discurso de verdade em que ela se apresenta.

O fato é, que há normas que se apresentam "aparentemente" com uma finalidade objetiva, real, concreta e até mesmo de bons propósitos, como por exemplo a Lei n. 6.938, de 31/8/1981 que dispóe sobre a Política Nacional do Meio Ambiente (BRASIL, 1981), amplamente propagada como a lei que instituía rígidos mecanismos de combate a degradação ambiental, proteção ao meio ambiente, imposição de regras de responsabilização.

O legislador, bem como a mídia em geral, difundiram a ideia de que essa lei, seria de inestimável potencial para a proteção ao meio ambiente. Muitos anos já se passaram desde a sua edição. Entretanto, o que se verifica facilmente é que, apesar de sua importância, o respectivo comando de conteúdo sancionatório não restou suficiente para coibir ou mesmo impedir as práticas nocivas à natureza. No mesmo caminho, a edição dessa norma não conduziu o legislador e mesmo os órgãos executivos, ao aperfeiçoamento constante de medidas essenciais à proteção ao meio ambiente. É possível constatar facilmente, por dados divulgados, que desde a edição da referida norma os desmatamentos aumentaram ${ }^{7}$,

7 Segundo o (INPE) Instituto Nacional de Pesquisas Espaciais, o desmatamento da Amazônia cresceu $29 \%$ entre o período de agosto de 2012 e julho de 2013 (cf. FLECKl; VALLONE, 2014). 
o volume de rios e lagos poluídos não diminuíram, a ausência de tratamento de esgoto ainda persiste e as matas ciliares continuam sendo destruídas e a mata atlântica está reduzida a poucas manchas em todo território brasileiro.

Não é difícil perceber que essa lei, que, aparentemente, visa atender determinada finalidade, qual seja, a proteçáo ao meio ambiente, acaba por desviar-se de seus objetivos, fato que contribui para a obtenção de poucos resultados, tendo em vista que foram atendidos os propósitos que verdadeiramente deram origem a norma aparente.

Essa situação é tão ou mais grave que a legislação simbólica clássica, aquela que não produz nenhum resultado proposto, uma vez que expóe e induz a uma "aparente" satisfação social, aliado a uma equivocada sensação de atendimento aos fins apresentados pela norma, quando efetivamente, a realidade que se apresenta não é a espelhada na lei.

A constatação de alguns resultados obtidos com as previsôes legais da norma aparente, como a divulgação de aplicação de elevadas multas a empresas que contaminaram rios e córregos (CSN, 2013), por exemplo, alimenta e fortalece a falsa sensação construída de que em decorrência daquele texto legal os problemas de degradação ambiental estariam resolvidos, criando um conformismo situacional e a consequente aquietação social ${ }^{8}$ diante de grave problema que exige maior atenção dos órgãos estatais, qual seja, o aperfeiçoamento da gestão pública.

A legislação aparente acaba por atender muito mais aos fins ideológicos ocultos que verdadeiramente a originaram, do que seus propósitos aparentemente apresentados a sociedade, o que ocorre também, em especial, em relação à proteção ao meio ambiente, como examinado adiante.

\section{A Legislação Aparente na Construção de uma Constitucionalização Sim- bólica}

Para muitos autores, a própria concepção constitucional está atrelada a um processo ideológico de formação sociológica do Estado, como no entendimento de Lassale (2010, p. 45), para quem "a verdadeira Constituição de um país somente tem por base os fatores reais e efetivos do poder que naquele país regem”.

Contudo, não seria a oportunidade para discorrer sobre a análise do Poder Constituinte e seus contornos políticos e históricos de formação. O que realmente interessa neste momento é verificar e identificar situaçóes de ausência de efetividade constitucional em atendimento a uma orientação interpretativa situada no plano ideológico ou por ele

8 "O que transforma uma crença em ideologia não é sua validade ou falta de validade, mas unicamente sua capacidade de controlar os comportamentos em determinada situação” (ABBAGNANO, 2007, p. 616). 
fortemente influenciada, em especial, diante da legislação específica, os seus efeitos na proteção ao meio ambiente.

É fato que "a norma constitucional não tem existência autônoma em face da realidade" (HESSE, 1991, p. 14), ou seja, a sua existência se apresenta na sua vigência, na concretização de seus enunciados normativos diante da realidade, o que Hesse (1991, p. 14-15) chamou de "pretensão de eficácia”.

A Constituição como norma fundamental mantém forte estabilidade em sua estrutura de texto, opondo-se a qualquer intenção facilitadora de modificação, como forma de assegurar a confiança de sua força normativa (HESSE, 1991, p. 22). Isso náo quer dizer, que sua interpretação seja estanque, insuscetível de alteração, principalmente ao longo do tempo. Ao contrário, é justamente a interpretação constitucional a força vital de sua eficácia, impondo no momento de sua concretização, vinculação com a realidade histórica concreta de seu tempo (HESSE, 1991, p. 25).

Náo se pode deixar de compreender que a positividade do direito o conduz a um sistema operacionalmente fechado, e que, como muito bem acentuou Neves (2011, p. 69-70), "a validade e o sentido do direito constitucional dependem da atividade legislativa e da aplicação concreta do direito".

A Constituição aqui, pode ser compreendida "como normatização de processos de produção normativa, imprescindível à positividade como autodeterminação operativa do direito" (NEVES, 2011, p. 71).

Essa função normativa da Constituição fixará limites ao sistema jurídico, e permitirá, por meio de evolução interpretativa, sua atualização histórico-social, equilibrando sua rigidez de "norma fundamental" à necessidade de alcance social almejado, muitas vezes já manifestada em comportamentos, possibilitando por meio de processo de concretização constitucional, aproximação entre Constituição e realidade social ${ }^{9}$.

Essa concretização constitucional não pode ser concebida como "hierarquização absoluta", mas como processo de circularidade entre "criação e aplicação do direito", em que as leis ordinárias e as decisões dos Tribunais competentes para questóes constitucionais "determinam o sentido e condicionam a validade das normas" (NEVES, 2011, p. 72).

É justamente no momento de interpretação da norma constitucional, nesse processo de circularidade, que se dá com certa frequência, forte influência da legislação aparente.

9 Neves (2011, p. 64), ao expor sobre a concepção cultural-dialética de Constituição, baseando-se em obras de Kelsen, Jellinek e, principalmente, Smend, afasta qualquer compreensão de norma constitucional como "expectativa estabilizada de comportamento", para assumir a relação dialética existente entre as expectativas jurídico-normativas de comportamento e as normas constitucionais vigentes, numa interação entre sistemas sociais. 
Esse fato age como inibidora de eficácia plena ou modificadora do contexto histórico do texto da Constituição, impedindo maior alcance de seus efeitos.

A complexidade das relaçôes sociais e a dinâmica de sua evolução vão exigir do intérprete constitucional o desenvolvimento argumentativo de convicçóes para fazer impor o caráter de "não identificação" da Constituição a qualquer preceito moral, religioso, filosófico ou ideológico totalizante (NEVES, 2011, p. 73), que possa se apresentar no contexto de uma legislação infraconstitucional.

O surgimento de uma constitucionalização simbólica baseada na influência de legislação aparente não se confunde com nenhum dos modelos apresentados por NEVES (2011, p. 90-104), seja por insuficiência de concretização normativo-jurídica generalizada do texto constitucional, seja em sentido positivo por meio de função político-ideológica da atividade constituinte do texto constitucional ou como constituição álibi.

Em todas essas formas de constitucionalização simbólica, há uma vinculação à inexistência de resultados de vigência da norma constitucional, informando a "falta generalizada de concretização das normas constitucionais ${ }^{10 "}$ (NEVES, 2011, p. 92), e ausência abrangente dessa concretização normativa do texto constitucional, ou seja, (muda a redação para substituir ou seja) de poucos resultados, em razão, aqui, da influência político-ideológica.

Ressalte-se que essa vinculação aos resultados obtidos, ou seja, a normatividade e concreção da norma constitucional, é elemento fundamental para Neves na caracterização da constitucionalização simbólica, como afirma:

A constituição funciona realmente como instância reflexiva de um sistema jurídico vigente e eficaz.

Já no caso da constitucionalização simbólica, à atividade constituinte e à emissão do texto constitucional não se segue uma normatividade jurídica generalizada, uma abrangente concretização normativa do texto constitucional. Assim, como já afirmei em relação à legislação simbólica (cf. Item 6, Cap. I), o elemento de distinção é também a hipertrofia da dimensão simbólica em detrimento da realização jurídico-instrumental dos dispositivos constitucionais.

Ocorre que há situaçôes em que o processo de interpretação do texto constitucional sofre forte influência da irradiação dos efeitos da legislação aparente, moldurada em seus

10 Nesse sentido, Neves (2011, p. 92) expõe uma das formas de constitucionalização simbólica, que se dá através da ausência generalizada de normatividade do texto constitucional, afirmando: "Ao texto constitucional não corresponde normatividade concreta nem normatividade materialmente determinada, ou seja, dele não decorre, de maneira generalizada, norma constitucional como variável influenciadora-estruturante e, ao mesmo tempo, influenciada-estruturada pela realidade a ela coordenada.” 
discursos de verdade ${ }^{11}$, finalisticamente atendendo a propósitos ideológicos, que irão produzir resultados efetivos, mas distintos de sua apresentação ao contexto social.

Esse processo de construção de constitucionalização simbólica, por influência de legislação aparente, se distingue dos demais modelos, diante de concretização normativa de textos constitucionais que produzirão resultados e aquietação social. Contudo, é possível perceber, que a interpretação dada ao texto constitucional foi alterada por absorção da ideia transmitida pela legislação aparente.

É possível utilizar o mesmo exemplo da Lei de Responsabilidade Fiscal, anteriormente mencionada, como aparente, para se verifique que embora sua vigência tenha proporcionado a obtenção de resultados positivos, no âmbito de aperfeiçoamento da responsabilidade na gestão pública, esses mesmos resultados estão longe de atenderem satisfatoriamente os propósitos da norma constitucional de controle das finanças públicas.

O objetivo "aparente" da norma infraconstitucional era o de regulamentar o art. 163 da CF, principalmente o inciso I, que dispóe sobre finanças públicas (BRASIL, 1988). Com mais de dez anos de vigência, porém, o descontrole dos gastos públicos continua, o endividamento público interno é altíssimo, as dívidas de final de mandato não cessaram e o inchaço da máquina pública com sobrecarga em sua despesa de pessoal é fato incontestável.

Essa norma (Lei de Responsabilidade Fiscal) de conteúdo “aparente” atingiu seu objetivo verdadeiro de atendimento ao mercado internacional e, embora internamente seus resultados sejam também positivos e perceptíveis, há um grave problema de acomodação conjuntural da sociedade - aquietação social - principalmente da classe política: não comprometimento público - que transformam o texto constitucional, sob tal influência, a ponto de limitar a interpretação normativa da Constituição ao alcance da norma infraconstitucional complementar.

\section{Os Efeitos da Legislação Aparente na Proteção ao Meio Ambiente}

Diante do exposto, não é difícil perceber, no caso específico do tratamento constitucional, alinhado à legislação referente à Política Nacional de Meio Ambiente, que o processo de elaboração legislativa sofreu a incidência político-valorativa, principalmente no decorrer de sua implementação/aplicação, causando, no âmbito da interpretação constitucional vigente, desvirtuamento de propósitos.

11 Entendemos ser oportunamente mais adequado a manutenção da análise partindo da concepção de Foucault sobre uma apresentaçâo ideológica conduzida por meio de uma linguagem que simula uma situação em detrimento de outra para justificação dos mecanismos de poder. Não desconhecemos as teorias que distinguem o agir comunicativo do agir estratégico, desenvolvido por Habermas e bem explicitado por Neves (2011, p. 116-120), que se enquadraria no debate proposto. 
Esses processos ideológicos apresentam-se com clareza, a partir de discursos de rigidez da norma, como aplicação da responsabilidade objetiva e solidária, desnecessidade de apuração de culpa ou de dolo e imputação de elevadíssimas multas. É lógico que tudo isso é válido e tem sua parcela de contribuição. $O$ fato a ser questionado não é esse.

$\mathrm{Na}$ linha do debate, que deve ser mais amplo, exige-se postura mais eficiente do legislador e dos governantes, impóe avanços, levantamento dos resultados alcançados com a norma, a partir daí, fica evidente a estagnação e o conformismo ideológico, que restringe investimentos e a adoção de política mais austera, moderna e eficiente na proteção ao meio ambiente. Não adianta os discursos e a aparência de lei rígida se os danos aumentam a cada dia. Diversos são os elementos inseridos nos discursos atuais, que camuflam os processos ideológicos acentuados e alicerçados em interesses econômicos muito fortes.

É comum a justificativa de que o dano ao meio ambiente, na maioria dos casos, não permite sua recomposição ao estado anterior - recompor o que foi destruído ou degradado em sua forma original -, criando, dessa forma, permissivo legal que admite como meio de reparação a imposição de multa pecuniária. É certo que em muitos casos, realmente, não há meios para voltar à cena original do ambiente físico degradado, e a aplicação de multa é, sem dúvida, um instrumento de coibição e sanção. Não é contra isso, e só isso, que se apresenta contrário. O que passa a ocorrer, na verdade, é que o exercício permanente dessa prática causa dano e, em consequência, aplica-se multa. Nada, além disso, é construído como proposição evolutiva de instrumentos aptos a aprimorar o contexto de proteção ambiental, fato que leva à compreensão de que a reparação pecuniária, por si só, acaba representando conforto, até mesmo para a consciência dos governantes, tratando-se de política pública de proteção e reparação ambiental.

Isso se comprova com fartos índices que demonstram a ausência de investimentos no que se refere à prevenção, falta de pessoas habilitadas na fiscalização (déficits de agentes fiscais do IBAMA em áreas extensas de florestas), ausência de integração da gestão florestal (BALAZINA, 2009), implementação de mecanismos eficazes de ajustamentos e composiçôes para priorizar açóes reparativas por parte dos agentes causadores de danos ao meio ambiente. O que se percebe é que cada vez mais são noticiadas ações de madeireiros clandestinos na Amazônia, por falta de fiscalização suficiente em área tão extensa de floresta; derramamento de esgoto em rios e lagos, por falta de investimentos em saneamento básico; contaminação de rios e mananciais; pescas predatórias; destruição de matas ciliares por produtores rurais com argumentos sustentados no desenvolvimento da atividade agrícola e pecuária, contemporaneamente denominado agronegócio; poluição do ar por indústrias; contaminação de cursos d'água e lençol freático pelos residos sólidos (lixóes), em decorrência, principalmente, de legislação altamente permissiva.

Por outro lado, o debate sobre a competência legislativa apresentada pela Constituição Federal, em seu art. 24, I, VI, VII e VIII (BRASIL, 1988), determina 
ser concorrente entre União, Estados-Membros e Distrito Federal a competência para legislar sobre matérias relativas à proteção do meio ambiente, conservação da natureza, defesa do solo, proteção ao patrimônio paisagístico e responsabilidade por dano ao meio ambiente, que se mostrava inflexiva, tem se apresentado em franca evolução interpretativa, no sentido de avançar na compreensão de que, sendo o meio ambiente um bem de todos e responsabilidade de todos os entes, cabe aos municípios a competência legislativa para editar normas de regulamentação que visam a proteção, preservação e defesa da integridade do meio ambiente local. Nesse sentido, traz-se à colação, recente decisão do Supremo Tribunal Federal, no RE 673.681/SP, relator Ministro Celso de Mello, que em seu voto destacou:

Tenho por inquestionável, por isso mesmo, que assiste ao Município competência constitucional para formular regras e legislar sobre proteção e defesa do meio ambiente, que representa encargo irrenunciável que incide sobre todos e cada um dos entes que integram o Estado Federal brasileiro. (BRASIL, 2014)

Admitir cada vez mais, com amplitude, a possibilidade dos municípios exercerem sua autonomia constitucional de legislar em assuntos de seu interesse local, (art. 30 da $\mathrm{CF}$ ) assegura, de fato, a implementação de políticas públicas efetivas de proteção ao meio ambiente. Contudo, o contexto atual que se insere a norma geral de política nacional de meio ambiente, diante dos resultados que se apresentam, reflete, incontestavelmente, um distanciamento da concretizaçáo constitucional de proteçáo ao meio ambiente e a efetiva realidade social. Há uma característica elementar da incidência da legislação aparente, e sua influência interpretativa na constitucionalização simbólica, diante dos fracos resultados alcançados. Saliente-se que a Constituição Federal, no art. 225, caput, prescreve:

Todos têm direito ao meio ambiente ecologicamente equilibrado, bem de uso comum do povo e essencial à sadia qualidade de vida, impondo-se ao Poder Público e à coletividade o dever de defendê-lo e preservá-lo para as presentes e futuras geraçôes (BRASIL, 1988).

Esse comando constitucional, como se vê, obriga o Poder Público, (compreendendo a União, os Estados-Membros, o Distrito Federal e os Municípios) e a coletividade a cuidarem e conservarem o meio ambiente, por ser ele direito de todos a ser usufruído pela a atual e pelas as futuras geraçóes.

Todavia, o transcrito preceito constitucional, de relevante dicção, está numa direção enquanto o Poder Público e a coletividade em outra oposto. O Poder Público se omite e a coletividade, em geral, não cobra a efetivação da Constituição nesse particular e pior, as pessoas naturais e as pessoas jurídicas, sobretudo as empresas que produzem produtos químicos ou utilizam deles como insumo de suas produçóes, são poluidores contumazes. 


\section{Conclusões}

O discurso e até mesmo o debate sobre a defesa do Estado Democrático de Direito, como constantemente se depara, não deve ser restrito ao campo da indagação sobre a elaboração de novas normas e novas formas técnicas de interpretação. A tentativa que ainda se emprega, principalmente no espaço ocupado pelos legisladores pátrios, com o fito de buscar soluçôes para conflitos sociais mediante edição de nova lei que, milagrosamente, possa transformar a realidade em passo de mágica é equívoco, pois, ao contrário de contribuir, acaba por desconstruir avanços edificados ao longo do tempo.

A concepção de processo legislativo não pode mais se dar no campo de compreensão de simples "produtor de leis", sendo necessária a incorporação de elementos racionalizadores voltados para a concreção de regramentos cada vez mais ajustados aos anseios da realidade social, sob pena de continuarem a produção contínua de normas aparentes e simbólicas impregnadas de conteúdos ineficazes.

Assim, para que as regras de direito possam sempre cumprir finalidades de atendimento a uma equalização de direitos, impedindo sua utilização meramente como instrumento de manipulação e dominação social, é evidente a necessidade de inserção de mecanismos de argumentaçáo democrática e participativa nos processos elaborativos e interpretativos das normas, principalmente em relaçáo à aplicabilidade dos textos constitucionais. Por meio da argumentação participativa, via sociedade de intérpretes ${ }^{12}$, será possível "a superação dos discursos e práticas biopolíticas, que reduzem e limitam as possibilidades dos direitos e dos sujeitos" (GONTIJO; ARCELO, 2009), evitando o surgimento de legislação simbólica ou aparente, com vistas a efetividade mais realista e adequada aos preceitos constitucionais, buscando afastar ou amenizar os efeitos de uma incidência exclusivamente ideológica durante o desenvolvimento desses processos, em especial, como abordado, no que diz respeito à proteção ao meio ambiente e ao desenvolvimento sustentável.

\section{Referências}

ABBAGNANO, Nicola. Dicionário de filosofia. São Paulo: Martins Fontes, 2007.

BALAZINA, Afra. Apreensão de madeira cresce 629,5\% em SP. Folha de S. Paulo, São Paulo, 21 jan. 2009. Caderno Ambiente. Disponível em: <http://www1.folha.uol. com.br/ambiente/2009/01/492573-apreensao-de-madeira-cresce-6295-em-sp.sht$\mathrm{ml}>$. Acesso em: 15 maio 2015.

12 "No processo de interpretação constitucional estão potencialmente vinculados todos os órgãos estatais, todas as potências públicas, todos os cidadãos e grupos, não sendo possível estabelecer-se um elenco cerrado ou fixado com numerus clausus de intérpretes da Constituição.” (HABERLE, 2002, p. 13). 
BRASIL. Constituição (1988). Constituição da República Federativa do Brasil, 1988. Brasília: Senado Federal, 1988. Disponível em: <http://www.planalto.gov.br/ccivil_03/constituicao/constituicao.htm>. Acesso em: 15 maio 2015.

BRASIL. Lei n. 6.938, de 31 de agosto de 1981. Dispóe sobre a Política Nacional do Meio Ambiente, seus fins e mecanismos de formulação e aplicação, e dá outras providências. Diário Oficial da Uniáo, Brasília, 2 set. 1981. Disponível em: <www. planalto.gov.br/ccivil_03/leis/16938.htm>. Acesso em: 14 abr. 2015.

BRASIL. Lei n. 8.072, de 25 de julho de 1990. Dispóe sobre os crimes hediondos, nos termos do art. $5^{\circ}$, inciso XLIII, da Constituição Federal, e determina outras providências. Diário Oficial da Uniáo, Brasília, 26 jul. 1990. Disponível em: <www. planalto.gov.br/ccivil_03/leis/18072.htm>. Acesso em: 14 abr. 2015.

BRASIL. Supremo Tribunal Federal. Lei municipal contestada em face de Constituição estadual. Competência do Município para dispor sobre preservação e defesa da integridade do meio ambiente. Recurso Extraordinário n. 673.681-SP. Relator: Min. Celso de Mello; Recte.: Ministério Público do Estado de São Paulo; Proc.: Procurador-Geral de Justiça do Estado de São Paulo; Recdo.: Prefeito do Município de Mogi Mirim. Informativo STF, n. 77, 5 dez. 2014. Disponível em: <queimadas.cptec. inpe.br/ $\sim$ rqueimadas/material3os/RE_673681.pdf>. Acesso em: 15 maio 2015.

CRUZ, Álvaro Ricardo Souza. Hermenêutica jurídica e(m) debate: o constitucionalismo brasileiro entre a teoria do discurso e a ontologia existencial. Belo Horizonte: Fórum, 2007.

CSN é multada em R\$ 35 milhóes por contaminação no RJ. Veja, São Paulo, 8 abr. 2013. Caderno Economia. Disponível em: <http://veja.abril.com.br/noticia/economia/csn-e-multada-em-r-35-milhoes-por-contaminacao-no-rj/>. Acesso em: 15 maio 2011.

FLECK, Isabel; VALLONE, Giuliana. Dilma diz que Marina mente sobre Amazônia; desmatamento cresceu em 2013. Folha de S. Paulo, São Paulo, 23 set. 2014 (reportagem de Marcelo Leite, enviado especial a Nova York). Disponível em: <http:// www1.folha.uol.com.br/poder/2014/09/1521157-dilma-diz-que-marina-mente-sobre-amazonia-desmatamento-cresceu-em-2013.shtml>. Acesso em: 15 maio 2015.

FOUCAULT, Michel. Em defesa da sociedade. São Paulo: Martins Fontes, 2005.

GONTIJO, Lucas de Alvarenga; ARCELO Adalberto Antônio Batista. A biopolítica nos estados democráticos de direito: a reprodução da subcidadania sob a égide da constitucionalização simbólica. In: CONGRESSO NACIONAL DO CONPEDI, 18., São Paulo 2009. Anais... Disponível em: <http://www.publicadireito.com.br/ conpedi/manaus/arquivos/Anais/sao_paulo/2412.pdf>. Acesso em: 14 abr. 2015. 
HABERLE, Peter. Hermenêutica constitucional: a sociedade aberta dos intérpretes da constituição: contribuição para a interpretação pluralista e procedimental da Constituição. Porto Alegre: Fabris, 2002.

HESSE, Konrad. A força normativa da Constituição. Porto Alegre: Sérgio Antonio Fabris Editor, 1991.

KELSEN, Hans. Teoria pura do direito. 7. ed. São Paulo: Martins Fontes, 2006.

LASSALE, Ferdinand. O que é uma Constituição. Campinas: Servanda, 2010.

LOBO, M. Alexandre. Michel Foucault e a microfísica do poder. [s.d.]. Disponível em: <https://sites.google.com/a/webhumanas.net/www/michelfoucaulteamicrof\%C3\%ADsicadopoder>. Acesso em: 17 jun. 2011.

MASCARENHAS, Oacir Silva. A influência da mídia na produção legislativa penal brasileira. Âmbito Jurídico, Rio Grande, n. 83, dez. 2010. Disponível em: <http:// www.ambito-juridico.com.br/site/index.php?n_link=revista_artigos_leitura\&artigo_id=8727>. Acesso em: 14 maio 2015.

NEVES, Marcelo. A constitucionalização simbólica. 3. ed. São Paulo: Martins Fontes, 2011.

SANTOS, David de (Frei). Negros: a face real da Lei Áurea. 2003. Disponível em: <http://www.antroposmoderno.com/antro-articulo.php?id_articulo=312>. Acesso em: 14 maio 2015.

SILVA JÚNIOR Arnaldo. A legislaçáo aparente na construçáo de uma constitucionalização simbólica. Disponível em: <https://sites.google.com/a/webhumanas.net/ www/michelfoucaulteamicrof\%C3\%ADsicadopoder>. Acesso em: 17 maio 2015.

ZAFFARONI, Eugenio Raúl; PIERANGELI, José Henrique. Manual de direito penal brasileiro. 4. ed. São Paulo: Revista dos Tribunais, 2002. 